\title{
A fisheries acoustic multi-frequency indicator to inform on large scale spatial patterns of aquatic pelagic ecosystems
}

\author{
Verena M. Trenkel ${ }^{\mathrm{a}, *}$ and Laurent Berger ${ }^{\mathrm{b}}$
}

\author{
a Ifremer, rue de l'île d'Yeu, BP 21105, 44311 Nantes cedex 3, France \\ b Ifremer, BP 70, 29280 Plouzané, France \\ *: Corresponding author : Verena M. Trenkel, Tel.: +33 240374157 ; fax: +33 240374075 ; \\ email address : verena.trenkel@ifremer.fr
}

\begin{abstract}
:
Fisheries acoustic instruments provide information on four major groups in aquatic ecosystems: fish with and without swim bladder (tertiary and quaternary consumers), fluidlike zooplankton (secondary consumers) and small gas bearing organisms such as larval fish and phytoplankton (predominantly primary producers). We entertain that this information is useable to describe the spatial structure of organism groups in pelagic ecosystems. The proposal we make is based on a multi-frequency indicator that synthesises in a single metric the shape of the acoustic frequency response of different organism groups, i.e. the dependence of received acoustic backscattered energy on emitting echosounder frequency. We demonstrate the development and interpretation of the multi-frequency indicator using simulated data. We then calculate the indicator for acoustic water-column survey data from the Bay of Biscay and use it to create reference maps for the spatial structure of the four scattering groups as well as their small scale spatial variability. These maps provide baselines for monitoring future changes in the structure of the pelagic ecosystem.
\end{abstract}

\section{Highlights}

Fisheries acoustics provide information on four major scattering groups: fish with and without swim bladder, fluid like zooplankton and gas bearing organisms such as larval fish and phytoplankton. A multi-frequency indicator describing the spatial distribution of scattering groups in pelagic ecosystems is derived from multi-frequency acoustic data. Application to the Bay of Biscay provides reference maps for spatial pelagic structures and ecosystem monitoring.

Keywords: Acoustics ; Frequency response curve ; Monitoring ; EOF ; Ecosystem state 


\section{Introduction}

The structure of exploited ecosystems is generally described and monitored using a suite of indicators such as species richness and abundance based biodiversity indices. However, information on the species levels is not always available, which is why the concept of surrogate species has been developed. Surrogate species can be taxonomic groupings such as genus or families, one species group being indicative of the species richness of other species groups (Gaston, 2000), or any other environmental information that is supposed to be related to species richness (Magurran, 2004). The advent of remote sensing data has provided opportunities for deriving surrogate species estimators for terrestrial vegetation applications (see review in Rocchini et al. 2010). For example, Gould (2000) developed an estimator of plant species richness based on satellite imagery data.

Fisheries acoustic water-column data is a currently underused data source for monitoring changes in pelagic ecosystem state, in particular for deriving indicators making use of the distinctive acoustic frequency response of different organism groups (Trenkel et al., 2011). The main principles of fisheries acoustic data collection are i) the emission of acoustic energy at a given frequency by an echosounder installed on the hull of a survey vessel and ii) the registration of the energy reflected (backscattered) by marine organisms encountered by the emitted sound wave on its way from the ship hull to the sea floor. The acoustic backscattered energy is due to the acoustic impedance contrast between the organism and the sea water. The impedance of each organism is a function of the physical properties of its body (density and sound velocity in the organism). Gas containing bodies such as swim bladders of fish are strong scatterers as both density and sound velocity are small in gas compared to sea water (Figure 1). The dependence of the received acoustic backscattering energy on the acoustic emission frequency is due to the strong dependence of acoustic impedance on frequency (in particular around the resonance frequency) but is also related to the shape and the roughness of the marine organisms, this dependence is commonly referred to as frequency response (Simmonds and MacLennan, 2005). Backscattering data at several echosounder frequencies over many octaves are collected sequentially using separate emission units (so called transducers). The frequency response curve of an organism is obtained by plotting the backscattering energy against the echosounder emission frequency and joining the points. The acoustic frequency response of living and non-living organisms can be measured in situ (Berger et al., 2009) or in the laboratory (Conti and Demer, 2003). Several species groups have distinct frequency response curves in the frequency band from 10 to $200 \mathrm{kHz}$ (Figure 2a). Making use of this feature, information on species groups with similar scattering properties, so called scattering groups, can be extracted from acoustic backscatter data. The scattering groups could then act as surrogate species representing different functional groups in the food web (Table 1).

Multi-frequency acoustic information, i.e. backscatter data collected using several transducers with different frequencies, has been used before for apportioning acoustic backscatter energy to species (De Robertis et al., 2010; Korneliussen and Ona, 2002). These authors used the relative frequency response as a basic indicator, i.e. the backscattering energy at a given frequency relative to a reference frequency $(38 \mathrm{kHz})$. Further, a simple two frequency based indicator has been derived and applied in several ecosystems, though so far without any ground truthing to validate the interpretation (Ballón et al., 2011; Lezama-Ochoa et al., 2011). Godø (2009) suggested to derive ecosystem indicators from a larger multi-frequency backscattering spectrum, but this has not been done so far. Given that the actual frequencies are important for frequency response curves, such a multi-frequency indicator needs to account for the order and magnitude of acoustic frequencies for which acoustic data are available. The novel indicator we 
propose does this in contrast to existing indicators. In addition it easily accommodates data for any number of acoustic frequencies.

Here we propose an acoustic multi-frequency indicator that makes use of the differential frequency response of different scattering groups at a number of ordered frequencies and provides a means to map and monitor large scale patterns and changes in the distribution of the underlying pelagic scattering groups. We demonstrate the approach by deriving the spatial patterns of the pelagic ecosystem in the Bay of Biscay in the late 2000s and creating reference maps which can be used for monitoring future large scale changes in the pelagic ecosystem structure caused by environmental and anthropogenic pressures.

\section{Material and methods}

\subsection{Bay of Biscay case study}

Acoustic data were collected in the Bay of Biscay during the Pelgas surveys conducted in May from 2006 to 2010 from the research vessel Thalassa. The survey design consisted of transects perpendicular to the coast with fixed spacing, from $30 \mathrm{~m}$ to about $200 \mathrm{~m}$ depth. Thalassa is equipped with five Simrad ER60 echosounders (18, 38, 70, 120, $200 \mathrm{kHz}$ ) whose transducers are installed close to each other to ensure the different echosounders observe as much as possible the same scenes in accordance with the recommendations by Korneliussen et al. (2008).

Acoustic samples collected during daylight (4 am to $19 \mathrm{pm} \mathrm{GMT)}$ in the surface layer (10 to $30 \mathrm{~m}$ below sea surface) were treated in the following way. For each frequency, backscattering coefficients $s_{V}$ were first corrected for the electronic delay in the echosounder and transducer. Second, they were thresholded at $\log 10(-85 / 10)$ to minimize the effect of background noise. Third, they were integrated per voxel (20 m along ship track, $5 \mathrm{~m}$ in depth direction) using the Movies software (Trenkel et al., 2009).

Acoustic attenuation due to vessel and wind induced air bubbles in surface layers depends on the size of the bubbles and the transducer frequency used (Dalen and Løvik, 1981; Novarini and Bruno, 1982). To minimize this effect, acoustic data collected at wind speeds above twenty knots were removed as for higher wind speeds acoustic measurements are degraded (Trenkel and Berger unpublished results). Further, only data acquired at vessel speeds above six knots were retained; fish reactions during slower trawling operations influence acoustic target strength and hence the frequency response (Cutter Jr and Demer, 2007). These data pre-treatment steps led to large areas with no data in 2007, hence 2007 was excluded.

\subsection{Acoustic multi-frequency indicator}

The aim of developing an acoustic multi-frequency indicator is to summarize acoustic data collected at several echosounder frequencies into a single multi-frequency indicator which retains the distinction between differently shaped curves in figure $2 a$. Interpretation of the indicator values with reference to empirical or modelled values of different organism groups should then allow to extract information from in situ data on the three-dimensional (depth and geographic area) distribution of different scattering groups. 
The proposed multi-frequency indicator I resembles a diversity indices commonly used for measuring species diversity that is based on pairwise comparisons between species abundances. In this case it measures the distribution of backscattering energy across echosounder frequencies with the peculiarity of respecting the ordering of echosounder frequencies, i.e. it distinguishes between an increasing and a decreasing frequency response curve. The indicator is derived from Rochet and Benoît (2012) who proposed it for measuring the shape of a biomass size spectrum (distribution of biomass across body size classes in a community). The multi-frequency indicator is defined as

$$
I=\left(\frac{\sum_{i} \sum_{l<i} d(i, I) D_{i} D_{\imath} e_{i} e_{l}}{\sum_{i} \sum_{l<i} D_{i} D_{l} e_{i} e_{l}}-0.4\right) / 0.6 .
$$

with $D_{\mathrm{i}}$ and $D_{1}$ the measured volume backscattering coefficient, $\mathrm{s}_{\mathrm{V}}$ in standard notation (MacLennan et al. 2002), for the ith and th echosounder frequency which has been scaled between 0 and 1 to obtain a relative frequency response curve (Figure 2b). The distance function $d(i, j)$ allows to account for the general shape of the frequency response curve, i.e. linear trend or trough/peak. It is defined as a function of the echosounder frequencies $f_{i}$ and $f_{i}$ for which data are available

$$
d(i, I)=1-\exp \left(-\left|f_{i}-f_{l}\right| / \delta\right)
$$

The form of $\mathrm{d}(\mathrm{i}, \mathrm{I})$ depends further on the value of the parameter $\delta$. Assuming backscattering coefficient data are available for five echosounder frequencies $(18,38,70,120$ and $200 \mathrm{kHz})$, setting $\delta=40$ amounts to giving weight 1 to the comparison of scaled backscattering energies at $18 \mathrm{~Hz}\left(D_{18}\right)$ and $200 \mathrm{kHz}\left(D_{200}\right)$ and intermediate weights to all other pairs (Figure 3a). Finally, $\mathrm{e}_{\mathrm{i}}$ and $e_{1}$ are additional weighting factors which allow to distinguish between increasing and decreasing curves as well as between a trough and a peak. For this they are set to the inverse of the frequency of the echosounder, $e_{i}=1 / f_{j}$. To spread the indicator roughly between 0 and 1 when data for only a small number of echosounder frequencies are available, the indicator is scaled between 0 and 1 by subtracting 0.4 and dividing by 0.6 .

To illustrate the behaviour of the multi-frequency indicator, values for differently shaped stylised frequency response curves are written next to each curve in figure $3 \mathrm{~b}$. The maximum indicator close to 1 is obtained for a u-shaped curve and slightly lower values for increasing curves with higher backscattering coefficients for the higher frequencies, e.g. at 120 and $200 \mathrm{kHz}$. The minimum indicator close to 0 corresponds to generally decreasing curves, that is those with higher backscattering coefficients at 18 and/or $38 \mathrm{kHz}$. Intermediate values are obtained for intermediate shapes.

\section{Calculation}

\subsection{Indicator interpretation}

To assign acoustically sampled cells in the water column to different scattering groups based on the calculated values of the multi-frequency indicator, a simulation study is carried out in this section. The seven scattering groups presented in figure 2 are assumed to cover all living and 
non-living aquatic scattering groups that are known to have more or less distinct acoustic frequency response curves. As before it is assumed that data are collected at five echosounder frequencies $(18,38,70,120,200 \mathrm{kHz})$, hence the considered frequency response curves only contain values at those five frequencies.

The schematic frequency response curves in figure 2 were extracted from the SIMFAMI project report (Fig. 9.29 in Fernandes et al., 2006). The two groups of fluidlike zooplankton are based on distorted-wave born approximation (DWBA) models (Stanton and Chu, 2000): small euphausiids (fluid bent cylinder) and copepods (fluid ellipsoid). Three fish groups are based on empirical data: mackerel, Scomber scombrus (a common weak scatterer without a swim bladder), deep phystostomes (swim bladder volume contracting with depth) and deep physoclists (swim bladder volume remaining constant with depth). In addition, the frequency response of small gas bubbles (0.1-0.2 mm equivalent radius) which exhibits a resonant peak at $38 \mathrm{kHz}$ was obtained from the DWBA model for a gaseous sphere (Stanton et al., 1998). Small gas bubbles are present in gas bearing organisms such as larval fish or phytoplankton and can be abundant in some ecosystems especially close to the surface. Finally, the frequency response of large gas bubbles (0.4-1.4 mm equivalent radius) was also derived from the DWBA model for a gaseous sphere. Large gas bubbles can stem from gas plumes seeping from the sea floor.

The relative frequency response curves in figure 2 are average values. To account for variations in real ecosystems, replicate curves were obtained by adding iid noise to the curves in figure $2 a$. This was done by drawing for each frequency from a normal distribution with mean 0 and standard deviation 1 (this value corresponds roughly to in situ values, e.g herring Saunders et al. (2012). Overall 500 replicate curves were created for each group. Then, for each replicate curve the multi-frequency indicator was calculated.

Figure 4 shows boxplots of replicate multi-frequency indices for each of the seven groups. The indicator values of several groups overlapped, leaving four distinguishable groups. The first group with the lowest values contained the two swim bladdered fish groups (deep phystostomes and deep physoclists) as well as large gas bubbles, the second group was made up of only small resonant gas bubbles, the third group of copepods and euphausiids, the fourth group, overlapping somewhat with the third one, consisted of mackerel.

For classifying sampling units using multi-frequency indicator values into the four major scattering groups the following guidelines were derived from the simulation results: $I<0.39 \mathrm{swim}$ bladder fish or large gas bubbles, $I=0.39-0.58$ small resonant bubbles present in gas bearing organisms such as larval fish and phytoplankton, $I=0.7-0.8$ fluidlike zooplankton such as copepods and euphausiids, and $I>0.8$ mackerel.

\subsection{Performance evaluation}

The capability of the multi-frequency indicator to correctly classify organisms into the correct group was evaluated using the simulations from the previous section. For this the interpretation guidelines were used to classify each replicate indicator value obtained for a replicate frequency response curve into one of the four distinct organism groups. The percentage of correct classifications was then calculated. These percentage correct classification values were compared to the two-frequency method by Ballón et al. (2011). Ballón et al. use the difference and sum between acoustic backscattering strengths at 38 and $120 \mathrm{kHz}$ to distinguish between fish and zooplankton only. 
Copepods and small euphausiids were both correctly classified as fluidlike zooplankton with a classification error of $10 \%$ for the former (Table 1). The two-frequency algorithm by Ballón et al. (2011) did similarly well. Mackerel had the highest misclassification rate of around $30 \%$ while small resonant bubbles were reliably classified using the multi-frequency indicator (13\% error). Similar results were obtained for swim bladder fish and large bubbles, for which the maximum error occurred for deep phyosclists ( $20 \%$ error). The two-frequency algorithm classified the majority of mackerel $(73 \%)$ and all small resonant bubbles in the fish group. Thus, using the multi-frequency indicator four instead of only two groups can be distinguished; importantly small resonant bubbles representing phytoplankton and fish larvae can be separated from fish.

\subsection{Describing and monitoring spatial patterns}

Using the multi-frequency indicator spatial, small-scale sampling units can be classified into four distinct scattering groups, from phytoplankton and fish larvae (small resonant bubbles), to zooplankton (euphausiids and copepods) and fish (mackerel and swim bladder fish). For describing 3D patterns of the pelagic ecosystem on a larger spatial scale, e.g. by depth band on a spatial grid of several nautical miles, the relative importance of each scattering group is obtained as the proportion of sampling units classified as a given scattering group. Mapping these proportions provides the relative spatial distribution of each group.

A more holistic way to summarize spatial patterns of the organisms in the pelagic ecosystem is to directly use the coefficient of variation (CV) of the multi-frequency indicator across sampling units. Areas with higher CVs would indicate a higher spatial heterogeneity in scattering groups, most of which are likely to be biological groups, compared to areas with lower values.

For monitoring purposes of the pelagic ecosystem in the context of ecosystem based ocean management, changes in the spatial distribution of the scattering groups and of the CV of the multi-frequency diversity indicator can be summarised using spatial indices (Woillez et al. 2009), or by directly comparing annual maps and extracting the persistent and changing features.

Empirical orthogonal functions (EOF) are a commonly used method for comparing and summarizing a series of maps (Preisendorfer 1988). EOFs decompose discrete spatial time series into a series of orthogonal (uncorrelated) dominant patterns of space and time. Denoting $\mathrm{F}(\mathrm{s}, \mathrm{t})$ the indicator value in spatial cell $s$ in year $t$, the decomposition carried out by EOF is

$$
F(s, t)=\sum_{m} \lambda_{m} u_{m}(t) e_{m}{ }^{T}(s)
$$

where $\lambda_{m}$ is the $m$ th non null eigenvalue, $e_{m}{ }^{T}(s)$ is the $m$ th eigenvector, also called EOF- $m$, which contains the spatial pattern and $u_{m}(t)$ is the mth principal component (time component) containing the amplitude, that is the temporal variations. For example, EOF-1 describes the major spatial pattern which is persistent across all maps (years). If calculated for a reference period, EOF-1 can be used as a spatial reference map for monitoring future changes in the pelagic ecosystem.

\subsection{Case study}

For the Bay of Biscay case study the multi-frequency indicator (eq. 1) was calculated per voxel (20 $\times 5 \mathrm{~m}$ sampling unit) which allowed to assign each sampling unit to one of the four scattering 
groups. Next the average proportion of each group was calculated on a regular spatial grid (20 $\mathrm{x}$ $20 \mathrm{~nm}$ ) in the surface layer; the CV of the multi-frequency indicator was calculated on the same spatial grid. To obtain reference maps, the annual maps were analysed with EOF using the Singular Value Decomposition method which works directly on the data matrix instead of the covariance matrix and is supposed to be more numerically stable (Venegas, 2001).

\section{Results}

\subsection{Spatial patterns of scattering groups}

The most important scattering group in the Bay of Biscay surface layer were fish with swim bladder $(50-70 \%)$, followed by small resonant bubbles which could be phyotplankton or fish larvae $(25-40 \%)$. Both fluidlike zooplankton and mackerel only dominated less than $2 \%$ of surface voxels in all study years.

Strong spatial patterns were found for all four scattering groups. EOF-1 explained $69 \%$ of spatiotemporal variability for swim bladder fish, $62 \%$ for small resonant bubbles, $44 \%$ for mackerel, and $42 \%$ for zooplankton. Hence the EOF-1 reference maps encapsulated well the average near surface situation in the period 2006-2010 (Figure 5). Small resonant bubbles were predominantly found on the shelf (Figure 5a) and zooplankton along the shelf edge and in the Gironde estuary (Figure $5 b$ ). The relative distribution for swim bladder fish was highest along the coast (Figure 5c) while that of mackerel was low in general with some higher areas along the shelf edge and near the Loire and Gironde estuaries (Figure $5 \mathrm{~d}$ ). For the CV of the multi-frequency indicator, $67 \%$ of spatio-temporal variability were explained by EOF-1 (Figure 6). The areas with the highest small scale variability were situated along the coast north of the Gironde and Loire estuaries and offshore in the northern part.

\subsection{Pelagic ecosystem reference maps}

The multi-frequency indicator provided a large scale image of the distribution of acoustic scattering groups and of their small scale variability (via its spatial coefficient of variation) in the Bay of Biscay. The EOF analysis extracted spatial reference maps based on the stable patterns for the study period (2006-2010).

Small resonant bubbles, which most likely were phytoplankton and fish larvae, were widespread in surface layers of most the area except near the coast. Fluidlike zooplankton cannot be observed within dense phytoplankton layers with the set of echosounder frequencies used in this study as their scattering is too weak compared to that of small resonant bubbles (Figure 2a). Thus the distribution of zooplankton was probably underestimated in certain areas dominated by phytoplankton. Nevertheless, the higher relative presence of zooplankton found in the middle of the continental shelf of the Bay of Biscay resembles the pattern observed by Irigoien et al. (2009) for large zooplankton in the same area based on direct sampling in May 1998 to 2006. Further, the zooplankton group identified here most likely corresponded to large copepods, as copepods are the dominant fluidlike zooplankton in the area (Irigoien et al., 2009). The smaller copepods observed near the coast by Irigoien et al. are also not easily observed with acoustic methods as the backscatter data are dominated acoustically by fish and resonant organisms. 
Swim bladder fish occur in dense schools, clusters of schools and more diffuse layers, where the actual structure seems to depend on environmental conditions (Petitgas et al., 2001). The proposed multi-frequency indicator should work well for all distribution forms as it does not consider absolute scattering density but only presence in a given sampling unit. The spatial reference maps for swim bladder fish showed strong stable spatial patterns which are however difficult to validate as no comparable maps for all swim bladder fish are available for the Bay of Biscay. However, single species maps for a small number of species such as anchovy, sprat and sardine show comparable spatial patterns (Trenkel et al., 2009).

Based on combining trawl information with acoustics, mackerel is thought to occur primarily along the shelf edge in the Bay of Biscay (ICES, 2010), which agrees well with the reference map established for mackerel in this study.

The reference situation for the small scale variability in the composition of acoustic scattering groups in the surface layer was one of higher variability in the central part of the continental shelf and near the estuaries of the two main contributories of the bay. A general comparison of these spatial patterns with other, for example species-based diversity indices is not possible as no study covering the whole Bay of Biscay is currently available.

\section{Discussion}

Two types of information were derived from acoustic multi-frequency data using a multifrequency indicator: relative spatial distributions of four scattering groups, fish with and without (mackerel) swim bladder, fluidlike zooplankton and small resonant bubbles (phytoplankton and larval fish), and the small scale spatial variability of these groups. This offers a rapid and automatic way to map the spatial distribution of scattering groups and their spatial variability as well as the possibility to create references maps for monitoring of pelagic ecosystems, as demonstrated for the Bay of Biscay.

Beyond providing reference maps, the information on scattering groups and their spatial variability could be used to study ecosystem structure and spatial relationships in the pelagic food web, such as the spatial relationship between zooplankton (preys) and fish (predators) (Lezama-Ochoa et al., 2011) or the relationship with environmental drivers (temperature, salinity...). The interannual variation in the spatial distribution of small pelagic species observed in the Bay of Biscay (Trenkel et al., 2009) might be explainable by the distribution of zooplankton or phytoplankton, i.e. small resonant gas bubbles.

The multi-frequency indicator values used to identify the scattering groups were derived in a somewhat ad hoc way from simulations conditional on five common echosounder frequencies $(18,38,70,120,200 \mathrm{kHz})$. If data from other echosounder frequencies were available, different multi-frequency indicator value ranges would apply for the same species groups. For example, research vessels, including Thalassa, are increasingly being equipped with a $333 \mathrm{kHz}$ echosounder. Using this additional frequency at the higher range is expected to allow improved identification of copepods in phytoplankton layers but requires retuning the indicator values used for scattering group classification. In any case, for refined interpretation and validation of the indicator values, improved knowledge of the scattering properties of different organisms especially for mixed species groups is required. For this, simultaneous in situ sampling by acoustics and complementary observation methods such as nets and videos (see review in Trenkel et al., 2011) will be needed. Further, instead of assigning each sampling unit uniquely 
to a given group, a more fuzzy assignment approach could be used which would allow overlapping ranges and accounting for the variability in frequency responses. One way to achieve this would be to assign a probability to belong to a given scattering group to each sampling units. These probabilities could be derived from the simulations presented here.

The application of the proposed method to the Bay of Biscay revealed large scale patterns in the reference maps for the pelagic ecosystem. Spatial resolution is a key issue in this analysis. The raw samples from each transducer were first averaged horizontally and vertically to reduce the expected stochastic variability in the measurement but also to increase the spatial overlap between the different echosounder beams steered from different locations with slightly different direction and beam opening. The voxel size for computing the multi-frequency indicator was chosen accordingly hence limiting the possibility to separate organisms that are close to each other, i.e. closer than $20 \mathrm{~m}$ in the horizontal direction and closer than $5 \mathrm{~m}$ in the vertical direction. An alternative method to this spatial averaging could be to extract objects using spatial contiguity at a given threshold for each frequency as proposed in the acoustic MOVIES3D software (Trenkel, et al. 2009). Differences in frequency response and differences between echosounder beam sampling volumes makes this method however inefficient for small objects.

The grid resolution selected for the EOF analysis of annual maps was also a compromise aimed at achieving both horizontally and vertically a spatial resolution consistent with the known spatial distribution of pelagic fish and plankton layers. The selected horizontal resolution, $20 \times 20$ nautical miles, is about four times larger than the average length of $5 \mathrm{~nm}$ of clusters of schools in the Bay of Biscay (Petitgas, 2003). Thus in the Bay of Biscay the reference maps are not influenced by the variable spatial distribution of school clusters. Different grid resolutions will be relevant in other ecosystems.

\section{Conclusions}

We proposed a multi-frequency indicator for deriving information regarding major scattering group distributions in pelagic ecosystems. With this multi-frequency indicator four instead of only two groups as with previous methods (Ballón et al. 2011) can be distinguished. Important for monitoring, small resonant bubbles representing phytoplankton and fish larvae can be separated from fish. The indicator then allows to summarise spatial distributions patterns and investigate small scale variability as demonstrated for the Bay of Biscay pelagic ecosystem. By extracting the stable spatial patterns reference maps for monitoring future changes can be created. Finally, though the indicator has much potential, in particular because of the large scale automatic data analysis it offers, detailed validation using field data when possible and modelling otherwise is advisable before using it for marine ecosystem based management.

\section{Acknowledgement}

Members of the EMH department of Ifremer in Nantes in charge of the PELGAS survey and crew of Ifremer's ship Thalassa made this work possible by collecting high quality acoustic data. This work received funding from the European Union Seventh Framework Programme project EURO-BASIN (ENV.2010.2.2.1-1) under grant agreement $n^{\circ} 264933$. 
Ballón, M., Bertrand, A., Lebourges-Dhaussy, A., Gutiérrez, M., Ayón, P., Grados, D., Gerlotto, F., 2011. Is there enough zooplankton to feed forage fish populations off Peru? An acoustic (positive) answer. Prog. Oceanogr. 91, 360-381.

Berger, L., Poncelet, C., Trenkel, V.M., 2009. A method for reducing uncertainty in estimates of fish school morphology and frequency response using data from multi-frequency and multibeam echo sounders. ICES J. Mar. Sci. 66, 1155-1161.

Conti, S.G., Demer, D.A., 2003. Wide-bandwidth acoustical charaterization of anchovy and sardine from reverberation measurements in an echoic tank. ICES J. Mar. Sci. 60, 617624.

Cutter Jr, G.R., Demer, D.A., 2007. Accounting for scattering directivity and fish behaviour in multibeam-echsounder surveys. ICES J. Mar. Sci. 64, 1664-1674.

Dalen, J., Løvik, A., 1981. The influence of wind-induced bubbles on echo integration surveys. J. Acoust. Soc. America 69, 1653-1659.

De Robertis, A., McKelvey, D.R., Ressler, P.H., 2010. Development and application of an empirical multifrequency method for backscatter classification. Can. J. Fish. Aquat. Sci. 67, 1459-1474.

Fernandes, P. G., Korneliussen, R.J., Lebourges-Dhaussy, A., Massé, J., Iglesias, M., Diner, N., Ona, E. 2006. The SIMFAMI project: Species identification methods from acoustic multifrequency information. Final report to the EC. Q5RS-2001-02054

Gaston, K.J., 2000. Global patterns in biodiversity. Nature 405, 220-227.

Godø, O.R., 2009. Technology answers to the requirements set the ecosystem approach. In Beamish, R. J. \& B. J. Rothschild (eds) The future of Fisheries Science in North America. Springer Science, 373-403.

Gould, W., 2000. Remote sensing of vegetation, plant species richnes, and regional biodiversity hotspots. Ecol. Appl. 10, 1861-1870.

ICES, 2010. Report of the Working Group on Acoustic and Egg Surveys for Sardine and Anchovy in ICES Areas VIII and IX (WGACEGG). ICES CM 2010/SSGESST:24, 204pp.

Irigoien, X., Fernandes, J.A., Grosjean, P., Denis, K., Albaina, A., Santos, M., 2009. Spring zooplankton distribution in the Bay of Biscay from 1998 to 2006 in relation with anchovy recruitment. J. Plankton Res. 31, 1-17.

Korneliussen, R. J., Diner, N., Ona, E., Berger, L., Fernandes, P.G., 2008. Proposals for the collection of multifrequency acoustic data. ICES J. Mar. Sci. 65, 982-994.

Korneliussen, R.J., Ona, A., 2002. An operational system for processing and visualizing multifrequency acoustic data. ICES J. Mar. Sci. 59, 293-313.

Lezama-Ochoa, A., Ballón, M., Woillez, M., Grados, D., Irigoien, X., Bertrand, A., 2011. Spatial patterns and scale-dependent relationships between macrozooplankton and fish in the Bay of Biscay: an acoustic study. Mar. Ecol. Prog. Ser. 439, 151-168.

MacLennan, D.N., Fernandes, P.G., Dalen, J., 2002. A consistent approach to definitions and symbols in fisheries acoustics. ICES J. Mar. Sci. 59, 365-369.

Magurran, A. E., 2004. Measuring biological diversity. Blackwell Publishing, Malden.

Novarini, J.C., Bruno, D.R., 1982. Effects of the sub-surface bubble layer on sound propagation. J. Acoust. Soc. America 72, 510-514.

Petitgas, P., 2003. A method for the identification and characterization of clusters of schools along the transect lines of fisheries-acoustic surveys. ICES J. Mar. Sci. 60, 872-884.

Petitgas, P., Reid, D., Carrera, P. Iglesias, M. Georgakarakos, S., Liorzou, B., Massé, J., 2001. On the relation between schools, clusters of schools, and abundance in pelagic fish stocks. ICES J. Mar. Sci. 58, 1150-2001. 
Preisendorfer, R., 1988. Principal Component Analysis in Meteorology and Oceanography. Elsevier, Amsterdam.

Rocchini, D., Balkenhol, N., Carter, G.A., Foody, G.M., Gillespie, T.W., He, K.S., Kark, S., Levin, N., Lucas, K. , Luoto, M., Nagendra, H., Oldeland, J., Ricotta, C., Southworth, J., Neteler, M. 2010. Remotely sensed spectral heterogeneity as a proxy of species diversity: Recent advances and open challenges. Ecol. Informatics 5, 318-329.

Rochet, M.-J., Benoît, E., 2012. Fishing destabilizes the biomass flow in the marine size spectrum. Proc. Roy. Soc. Series B 279, 284-292.

Saunders, R.A., O'Donnell, C., Korneliussen, R.J., Fässler, S.M.M., Clarke, M.W., Egan, A., Reid, D., 2012. Utility of $18-\mathrm{kHz}$ acoustic data for abundance estimation of Atlantic herring (Clupea harengus). ICES J. Mar. Sci. 69, 1086-1098.

Simmonds, E. J., MacLennan, D.N., 2005. Fisheries Acoustics. Theory and practice, 2nd edition edn. Blackwell, Oxford.

Stanton, T. K., Chu, D. 2000. Review and recommendations for the modelling of acoustic scattering by fluid-like elongated zooplankton: euphausiids and copepods. ICES J. Mar. Sci. 57, 793-807.

Stanton, T.K., Chu, D., Wiebe, P.H., Martin, L.V., Eastwood, R. L., 1998. Sound scattering by several zooplankton groups. I. Experimental determination of dominant scattering mechanisms. J. Acoust. Soc. America 103, 225-235.

Trenkel, V.M., Berger, L., Bourguignon, S., Doray, M., Fablet, R., Massé, J., Mazauric, V., Poncelet, C,. Quemener, G., Scalabrin, C., Villalobos, H., 2009. Overview of recent progress in fisheries acoustics made by Ifremer with examples from the Bay of Biscay. Aquat. Liv. Res. 22, 433-445.

Trenkel, V.M., Ressler, P.H., Jech, M., Giannoulaki, M., Taylor, C., 2011. Underwater acoustics for ecosystem-based management: state of the science and proposals for ecosystem indicators. Mar. Ecol. Prog. Ser. 442, 285-301.

Venegas, S.A., 2001 Statistical methods for signal detection in climate. DCESS Report No 2. 6pp www.atmos.colostate.edu/ davet/AT655/notes/VenegasNotes.pdf

Woillez, M., Rivoirard, J., Petitgas, P., 2009. Notes on survey-based spatial indicators for monitoring fish populations. Aquat. Liv. Res. 22, 155-164. 
Table 1. Simulation based percentage correct classification rate of organisms belonging to different scattering groups using multi-frequency indicator (this study) and two-frequency algorithm (Ballón et al. 2011).

\begin{tabular}{|c|c|c|c|c|c|c|c|}
\hline \multirow[b]{3}{*}{$\begin{array}{l}\text { Functional } \\
\text { group }\end{array}$} & \multirow[b]{3}{*}{$\begin{array}{l}\text { True } \\
\text { scatterer } \\
\text { group }\end{array}$} & \multicolumn{6}{|c|}{ Identified scatterer group } \\
\hline & & \multicolumn{4}{|c|}{ Multi-frequency indicator } & \multicolumn{2}{|c|}{$\begin{array}{l}\text { Two-frequenc\} } \\
\text { algorithm }\end{array}$} \\
\hline & & $\begin{array}{l}\text { fluidlike } \\
\text { zooplankton }\end{array}$ & mackerel & $\begin{array}{l}\text { small } \\
\text { bubbles }\end{array}$ & $\begin{array}{l}\text { swim } \\
\text { bladder fish } \\
\text { \& large } \\
\text { bubbles }\end{array}$ & fluidlike & fish \\
\hline $\begin{array}{l}\text { primary \& } \\
\text { secondary } \\
\text { consumers }\end{array}$ & $\begin{array}{l}\text { small resonant } \\
\text { bubbles } \\
\text { (phytoplankton } \\
\text { \& fish larvae) }\end{array}$ & 0 & 0 & 86.8 & 11.8 & 0 & 100 \\
\hline secondary & copepods & 90.2 & 9.8 & 0 & 0 & 100 & 0 \\
\hline consumers & $\begin{array}{l}\text { small } \\
\text { euphausiids }\end{array}$ & 100 & 0 & 0 & 0 & 100 & 0 \\
\hline \multirow{3}{*}{$\begin{array}{l}\text { tertiary \& } \\
\text { quaternary } \\
\text { consumers }\end{array}$} & mackerel & 20 & 70.4 & 1.4 & 0 & 27.2 & 72.8 \\
\hline & $\begin{array}{l}\text { deep } \\
\text { physoclists }\end{array}$ & 2.4 & 2.2 & 11.2 & 79.6 & 0.2 & 99.8 \\
\hline & $\begin{array}{l}\text { deep } \\
\text { phystostomes }\end{array}$ & 0.2 & 0 & 2.6 & 96.8 & 0 & 100 \\
\hline non-living & large bubbles & 0 & 0 & 0.2 & 99.6 & 0 & 100 \\
\hline
\end{tabular}

\section{Figures}

Figure 1. Schematic view of fisheries acoustics data collection (left) and data visualisation at a single frequency (right).
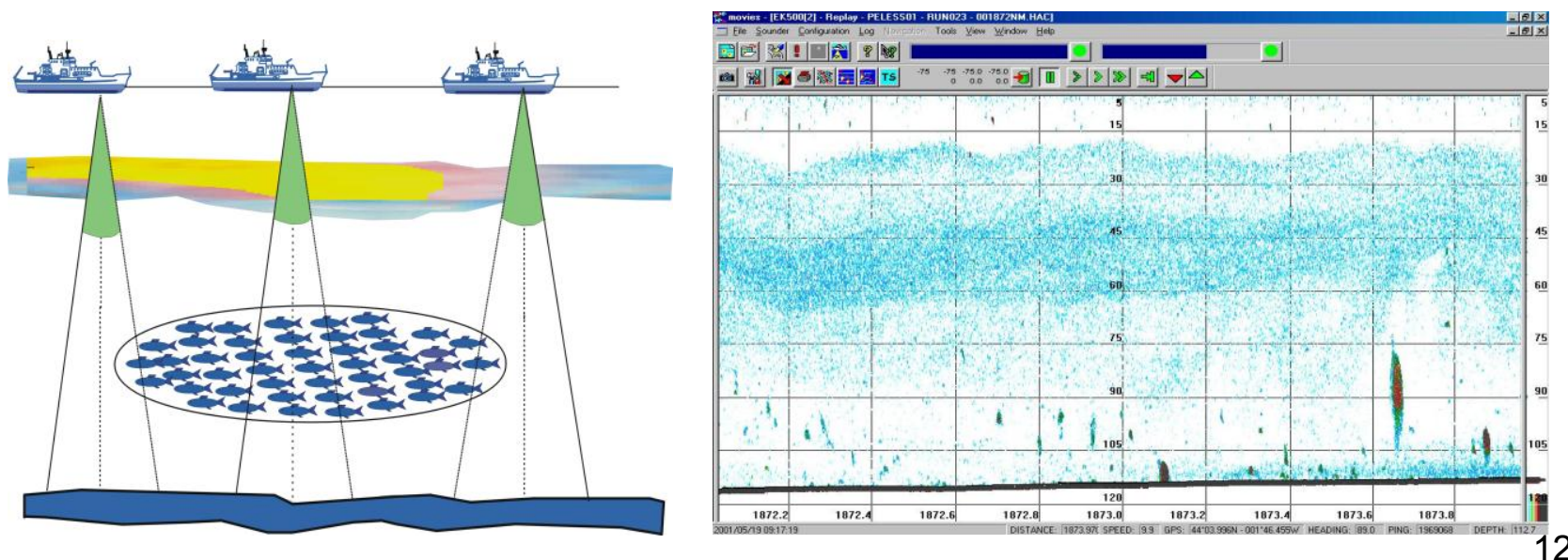
Figure 2. (a) Schematic fisheries acoustic frequency response curves for species groups and gas bubbles on scale of volume backscattering strength Sv (partially redrawn from Fernandes et al. (2006; Fig. 9.29); (b) Frequency response curves in (a) transformed to volume backscattering coefficients $\left(\mathrm{s}_{\mathrm{v}}=10^{\mathrm{sv} / 10}\right)$ and rescaled between 0 and 1 .
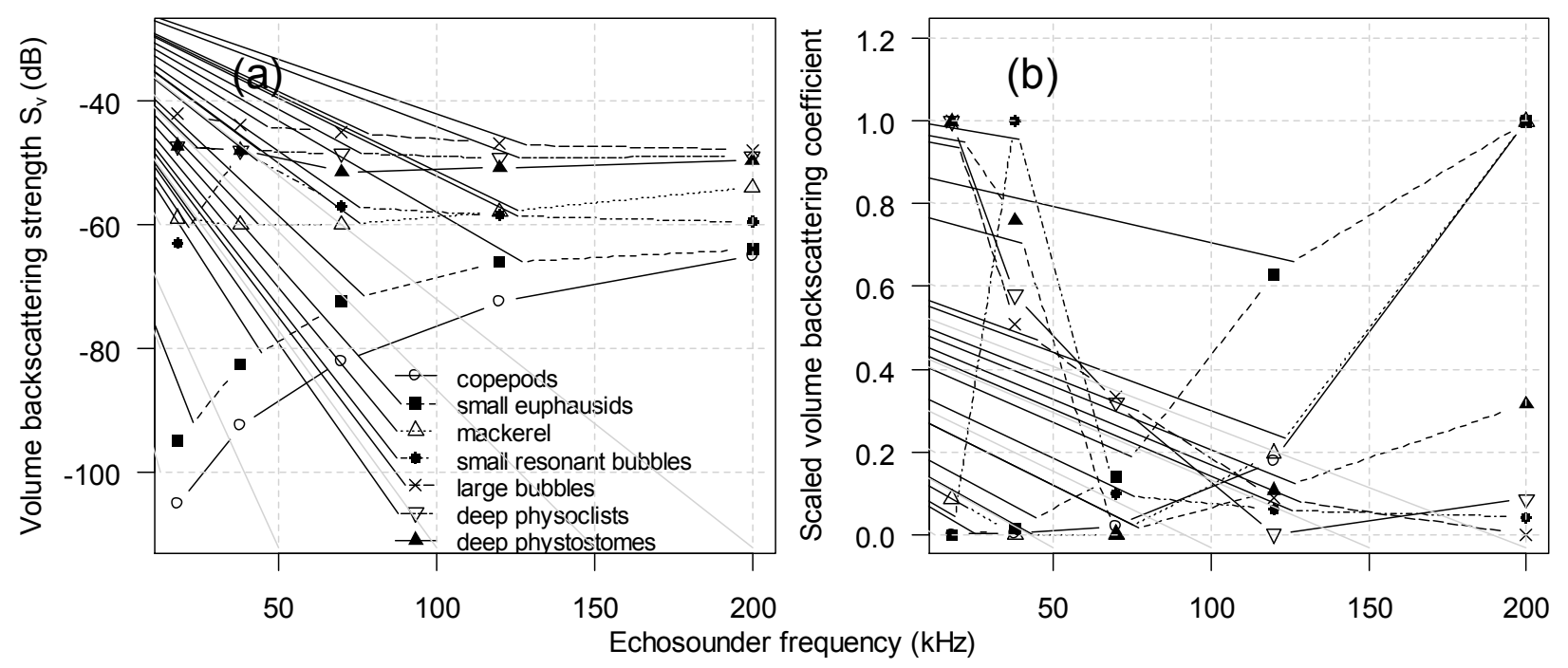

Figure 3. (a) Shape of distance weighting function $d(i, j)$ in acoustic multi-frequency indicator $I$ (eq. 1) as a function of absolute difference in echosounder frequency for different values of scaling parameter $\delta$. In bold the selected function. (b) Value of acoustic multi-frequency indicator $I$ for different typical frequency response curves. The values of $I$ increase as relatively more backscattered energy is measured at the most distant echosounder frequencies.

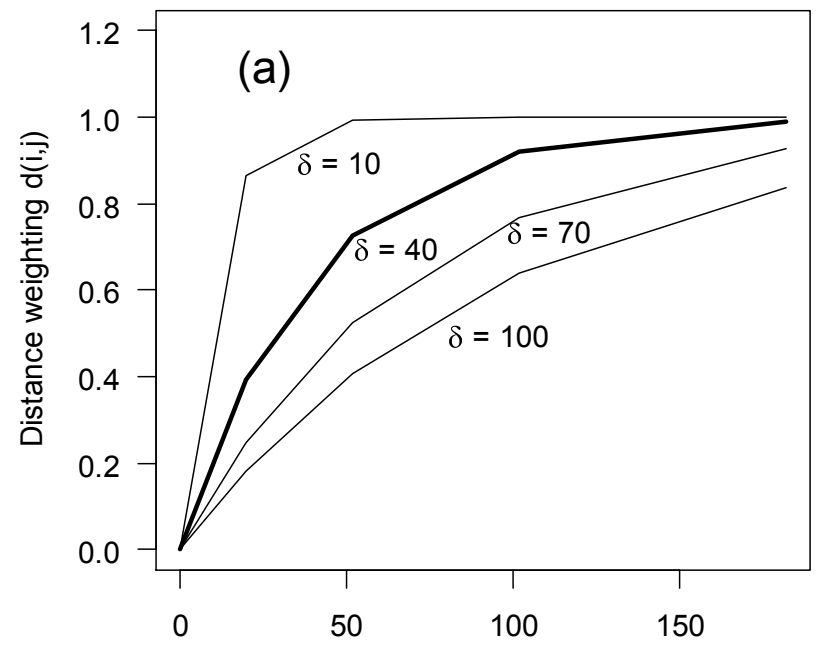

Echosounder frequency difference $|\mathrm{i}-\mathrm{j}|$

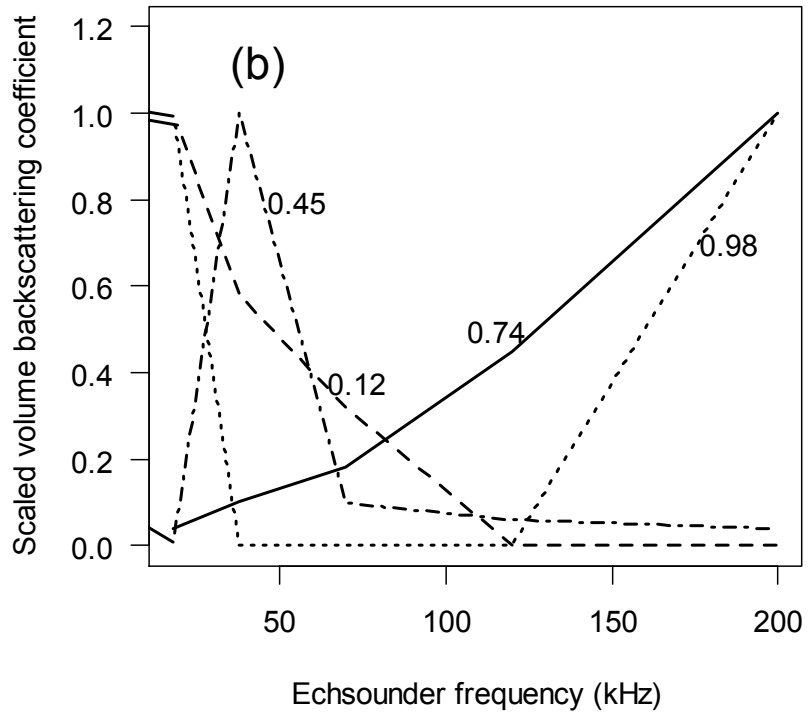


Figure 4. Boxplots of simulated multi-frequency response indices by species groups assuming iid distributed errors for frequency response curves in Figure 2a. The shaded areas indicate the range of values used to identify each species group using the multi-frequency indicator. Boxes span the 25th and 75th percentile, horizontal bars are medians and whiskers extend to the most extreme values. Stars are the results for the baseline curves in Figure 1.

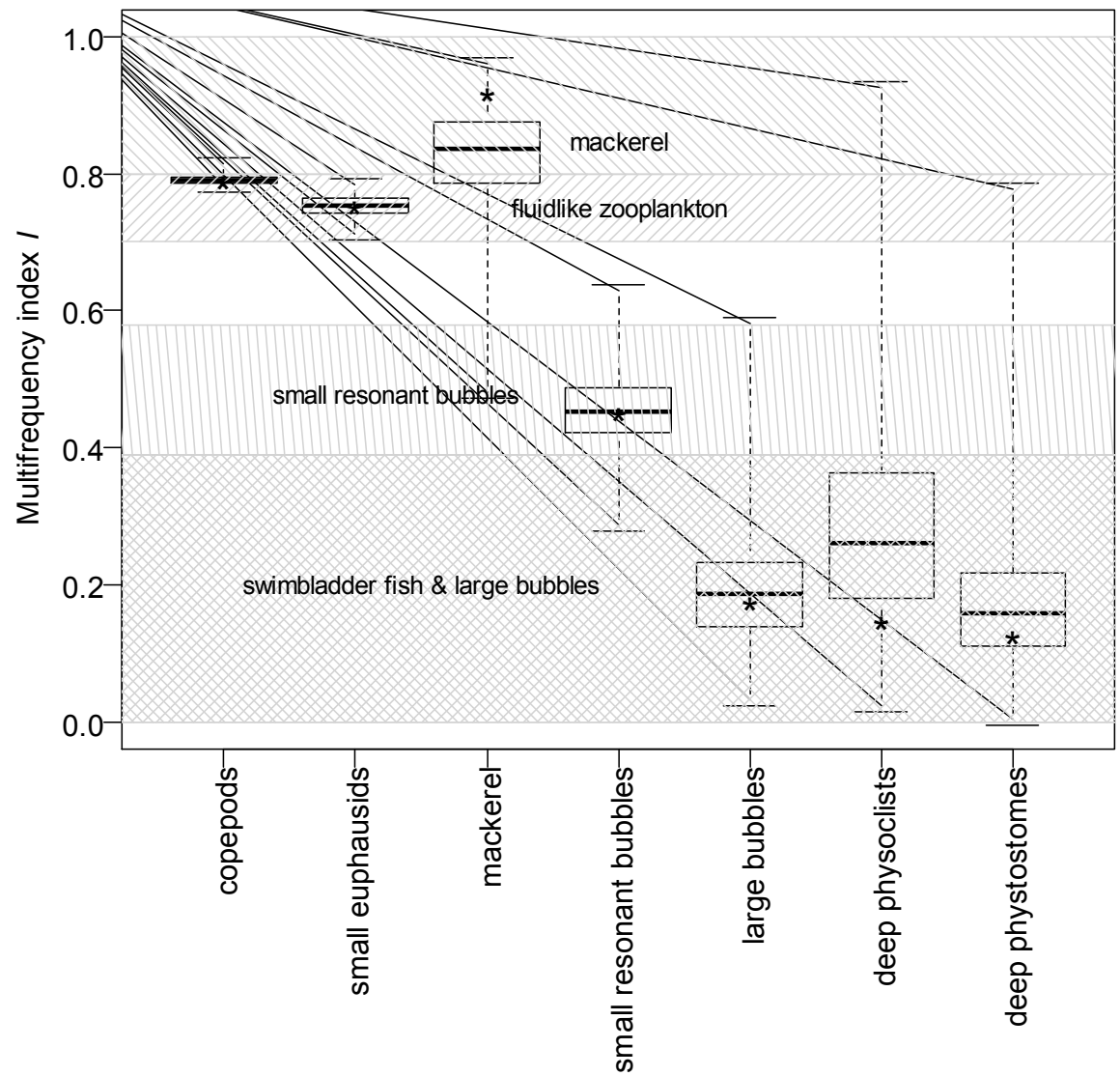


Figure 5. EOF-1 for the proportion of scattering groups in the Bay of Biscay surface layer (10-30 m below sea surface). (a) small resonant bubbles, e.g. phytoplankton and fish larvae, (b) fluidlike zooplankton, e.g. copepods and small euphausiids, (c) swim bladder fish, (d) fish without swim bladder, e.g. mackerel.
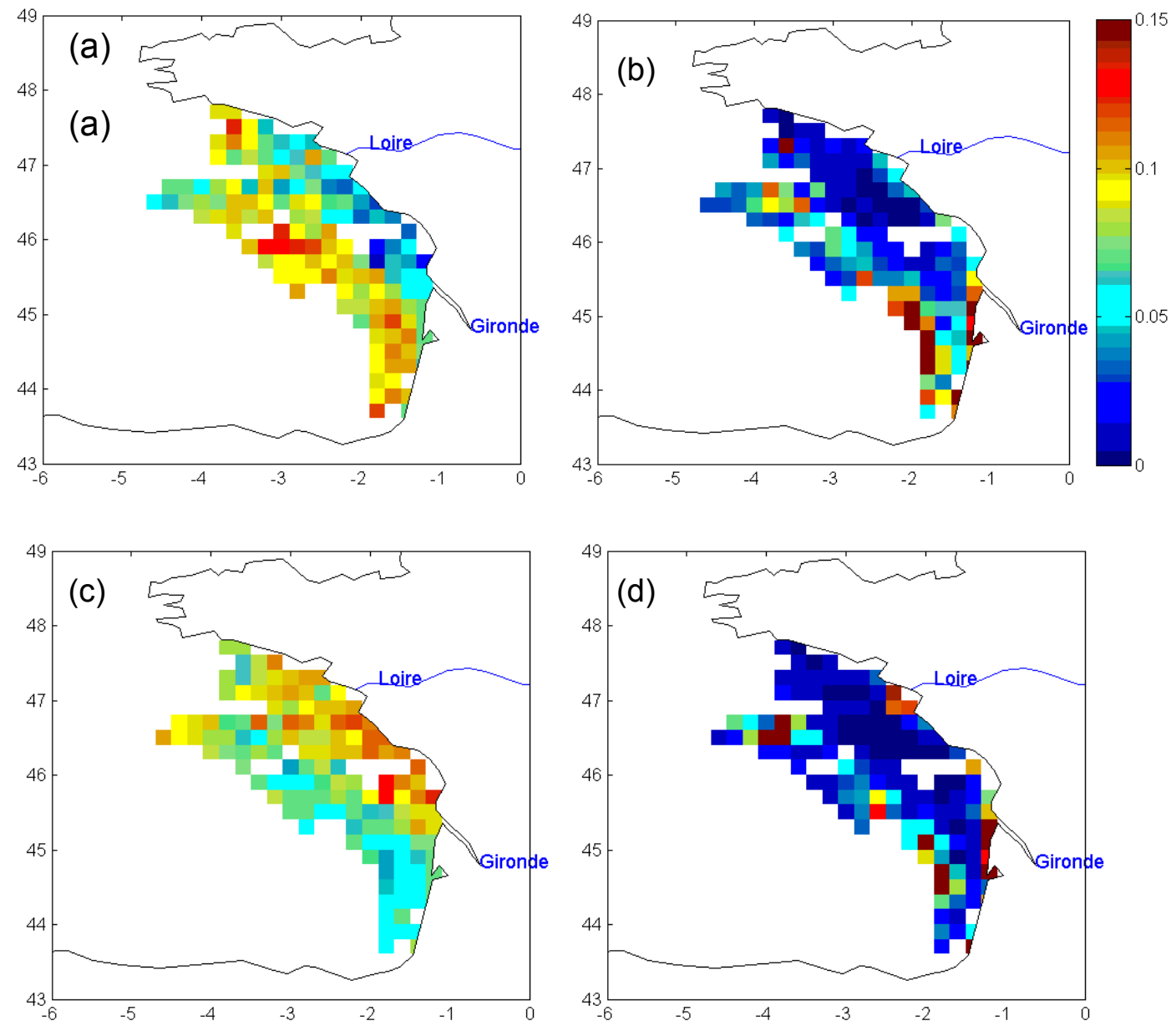

Figure 6. EOF-1 for the small scale spatial variation of the acoustic multi-frequency indicator in the Bay of Biscay surface layer (10-30 m below sea surface).

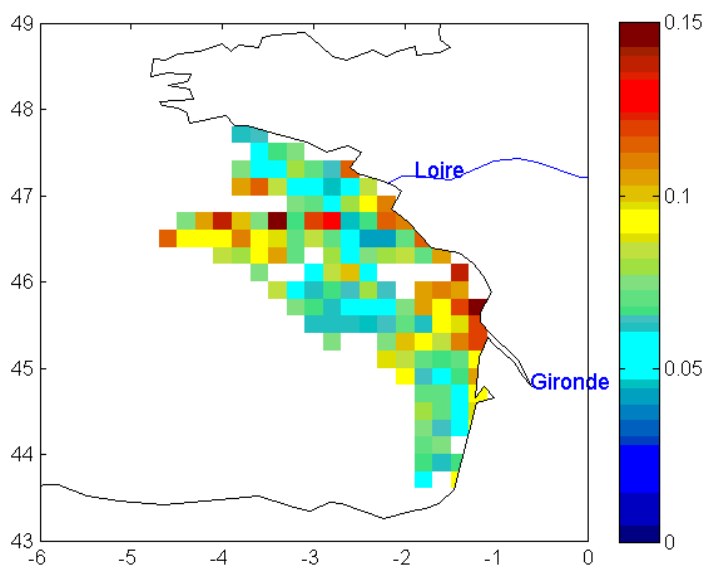

